\title{
TECNOLOGIAS SOCIAIS PARA A CONVIVÊNCIA COM O SEMIÁRIDO: USO DE CISTERNAS DOMICILIARES EM COMUNIDADES RURAIS DO CEARÁ
}

Rivania Teles ${ }^{1}$

Resumo: Esse estudo teve por objetivo avaliar a utilização de cisternas domiciliares e como esta tecnologia tem contribuído para melhorar as condições de vida da população nas comunidades rurais de Cajazeirinha e Minador, localizados no município de Ipaumirim, estado do Ceará. O estudo foi baseado em coleta de dados por meio da realização de entrevistas e questionários em agosto de 2019. Para avaliar a qualidade da água, foram colhidas amostras de água das cisternas, e do principal poço cacimbão para realizar análises físico-química e microbiológica. Para a análise físico-química foram verificados $\mathrm{o} \mathrm{pH}$, condutividade, sólidos totais, cloreto e dureza. $\mathrm{Na}$ análise microbiológica foram verificadas a presença ou ausência de coliformes totais a $30{ }^{\circ} \mathrm{C}$ e $45{ }^{\circ} \mathrm{C}$ em uma série de três: $10 \mathrm{ml} ; 1 \mathrm{ml} \mathrm{e} 0,1 \mathrm{ml}$. Foram utilizados replicagem em placas de Petri para identificar presença ou ausência de Escherichia Coli. Segundo os resultados da análise físico-química a água possui uma qualidade considerada dentro dos padrões de potabilidade e na análise microbiológica foi detectada uma baixa presença de coliformes totais, assim também como a ausência de E. Coli. A população estudada é constituída por 26 famílias, um total de 97 . De acordo com o resultado da investigação, concluiu-se que a efetivação de programas sociais de políticas públicas na região, de fato tem beneficiado a população a mitigar a escassez de água nos períodos de estiagem. A implantação das cisternas domiciliares melhorou consideravelmente a qualidade de vida da população, e todos na comunidade se mostraram satisfeitos com o uso da referida tecnologia social.

Palavra-chave: Políticas Públicas; Semiárido Brasileiro; Cisternas; Comunidades Rurais.

${ }^{1}$ Universidade de São Paulo. E-mail: rivaniateles@hotmail.com. 
Abstract: This study aimed to evaluate the use of household cisterns and how this technology has contributed to improve the living conditions of the population in the rural communities of Cajazeirinha and Minador, located in Ipaumirim, Ceará state. The study was based on data collection through interviews and questionnaires in August 2019. To assess water quality, water samples were collected from the cisterns and from the main well Cacimbão to perform physicochemical and microbiological analyzes. For the physicochemical analysis the $\mathrm{pH}$, conductivity, total solids, chloride and hardness were verified. Microbiological analysis showed the presence or absence of total coliforms at $30^{\circ} \mathrm{C}$ and $45^{\circ} \mathrm{C}$ in a series of three: $10 \mathrm{ml} ; 1 \mathrm{ml}$ and $0.1 \mathrm{ml}$. Petri dish replication was used to identify the presence or absence of Escherichia Coli. According to the results of the physicochemical analysis water has a quality considered within potability standards and microbiological analysis detected a low presence of total coliforms, as well as the absence of $\mathrm{E}$. Coli. The study population consists of 26 families, a total of 97. According to the result of the investigation, it was concluded that the implementation of social programs of public policies in the region, in fact, has benefited the population to mitigate water scarcity in the drought periods. The implementation of household cisterns considerably improved the population's quality of life, and everyone in the community was satisfied with the use of this social technology.

Keywords: Public Policy; Brazilian Semiarid; Cisterns; Rural Communities.

\section{Introdução}

A região do Semiárido Brasileiro ocupa cerca de $12 \%$ do território nacional abrangendo os estados do Piauí, Ceará, Rio Grande do Norte, Paraíba, Pernambuco, Alagoas, Sergipe, Bahia e parte do norte do Estado de Minas Gerais (Região Sudeste), considerada a região mais habitada do mundo com aproximadamente 27 milhões de habitantes (SUDENE/2017). A principal característica dessa região é o clima com baixa precipitação e secas prolongadas.

Influenciados por fenômenos naturais tais como o El Niño, que bloqueia as frentes frias vindas do Sul, a Zona de Convergência Inter Tropical e ainda em termos geológicos, "o embasamento cristalino, representados por $70 \%$ da região semiárida e as bacias sedimentares" (SUASSUNA, 2002), que impede o acúmulo de água principalmente nos subsolos, uma vez que, o solo da região assemelha-se a de um prato raso.

Essas características influenciam e acabam por dificultar a vida da população dessa região, onde o principal problema é a escassez de água. Sem o bem necessário à sobrevivência, a população sofre com o desabastecimento e dificulta atividades como a agricultura e a pecuária. Durante muito tempo esse foi o pensamento de muitos nordestinos assolados pelos longos anos a fio de seca. A fome e a desesperança provocaram mortes e o êxodo de boa parte da população para a região Sudeste do país, em busca de trabalho e melhores condições de vida, criando o estereótipo de que nessa região só existe seca, fome e pessoas em condições de vida muito difícil.

Mas ao contrário do que se pensa, o Semiárido Brasileiro é uma região tão importante e rica quanto outras regiões do país, dependendo da região seu 
solo é parcialmente fértil, tornando-se propício o cultivo de variadas culturas adaptáveis a nossa realidade climática. O que falta são ações e políticas públicas realmente eficazes para o desenvolvimento da região e subsídios para melhorar a vida da população local.

\section{Combate à seca versus convivência com o semiárido}

A seca sempre foi vista como um problema para a região nordeste, o clima semiárido característico da nossa região sempre existiu e nunca deixará de existir. Estudos mostram a preocupação com as consequências do fenômeno desde o século XIX, quando "em 1877, diante das terríveis consequências da grande seca, Dom Pedro II, imperador do Brasil, prometeu acabar com o sofrimento e a fome dos povos do semiárido, nem que, para isso, tivesse que vender a última joia da Coroa". (BAPTISTA; CAMPOS, p. 27, 2013). Acreditando o imperador que o fenômeno poderia ser facilmente resolvido com dinheiro, e que somente a seca era causadora das calamidades sertanejas.

Essa mentalidade se arrastou por décadas, onde os governantes procuravam a todo custo soluções para combater a seca na região. No entanto, diante das calamidades ocasionadas pelas sucessivas secas, como a fome e a morte de centenas de pessoas, começaram a serem criados órgãos governamentais que promovessem ações para solucionar o problema em questão. Em 1909, foi criada a Inspetoria de Obras Contra as Secas (IOCS), mais tarde substituída pelo Departamento Nacional de Obras Contra as Secas (DNOCS).

As ações se voltaram para a construção de açudes, barragens, poços e de estradas, tornando-se uma das principais medidas de solução. Porém, não se mostrou eficaz e as dificuldades continuaram a persistir, pois, nem toda a população tinha acesso a essas ações, como por exemplo, os açudes eram construídos em locais distantes ou em propriedades particulares, tornando-os inacessíveis. Deste modo:

Diante da baixa eficácia do modelo de política adotado, o cenário recorrente de calamidade impunha ao governo federal a necessidade de se adotar medidas emergenciais para socorrer a população. A utilização de caminhõespipa para distribuir água foi uma medida emergencial que se tornou padrão nas últimas décadas do século XX. Destarte, a carência de medidas estruturantes que solucionassem o problema passou a ser contornada por soluções paliativas, de modo que a população se tornou dependente das ações emergenciais (ANDRADE, 2014, p. 31). 
Mais uma ação frustrada do governo que se mostrou de baixa eficácia, tornado apenas uma medida paliativa, de modo que, a população vivia dependente e a espera de ações emergenciais que na verdade nunca iria solucionar o problema. Para tanto, no intuito de resolver o problema da seca no Nordeste programas governamentais têm criado estratégias que visavam o "combate à seca". No entanto, não se pode mudar o clima que temos, mas buscar nos adaptar a ele através de políticas públicas eficazes.

Não se pode combater ecossistemas, variações climáticas, direção de ventos e o sol. É preciso haver políticas públicas que façam a região produzir de maneira segura para si e para o mercado, viver sem catástrofe, exatamente com este clima que temos. Queremos conviver com o clima que existe aqui há 8 ou 10.000 anos, onde, com alguns anos de muita chuva e outros com pouca, a natureza criou um sistema ecológico único, de grande riquezas e variedade (SCHISTEK, 2013, P. 32-33).

O clima semiárido está presente em diversas partes do mundo, caracterizado por altas temperaturas, baixa precipitação, chuvas irregulares e escassas. Por esse motivo, regiões que apresentam esse tipo de clima sofrem com problemas sociais, econômicos e ambientais, gerados pela escassez de água, dificultando o desenvolvimento de atividades como a agricultura e pecuária. Problemas ambientais relacionados tanto as condições climáticas quanto as ações antrópicas, a exemplo, desmatamento, práticas inadequadas da agricultura, manejo irregular do solo, desertificação, entre outros.

No Brasil, o êxodo rural é um dos principais problemas sociais enfrentados pela população, tornando-se uma válvula de escape para fugir das más condições de vida durante os períodos de seca na região. Diante disso, a seca tornou-se protagonista das catástrofes da região e perpetuando uma imagem negativa, um lugar de miséria, fome e seca. Conhecemos nossa realidade climática, a seca é um fenômeno natural consequência do nosso clima não há meios que possa mudá-lo, mas de convivência.

Ultimamente, tem-se ouvido muito o termo Convivência com o Semiárido, uma espécie de nomenclatura usada para substituir o famoso "combate à seca", busca-se agora medidas emergenciais como uma forma de tentar mitigar a situação da falta d'água. Ações governamentais e de instituições e associações não governamentais, tem desenvolvido propostas e ações que se mostraram eficazes na questão de que é possível viver e produzir mesmo com a falta ou com as poucas chuvas na região. O clima que vivenciamos, não deve ser tratado como um vilão ou um empecilho pelo contrário devemos aprender a conviver com ele e usá-lo a nosso favor, nessa perspectiva: 
Esses diferentes enfoques e imagens historicamente construídas influenciam até hoje as propostas de desenvolvimento do semiárido brasileiro. Não se trata apenas de opções políticas diferentes quanto a uma problemática regional. Percebe-se que estas duas perspectivas,

do combate à seca e da convivência com o semiárido, estão estreitamente articuladas com diferentes paradigmas de desenvolvimento que informam as percepções sobre aquela realidade,

selecionam os problemas e os seus enfoques específicos e indicam os modelos válidos de intervenção na superação de seus problemas específicos (SILVA, p. 364, 2003).

As propostas de convivência com o semiárido buscaram mudar a forma de viver do homem sertanejo, compreendendo a partir da nossa realidade, que existe a possibilidade de viver bem no semiárido trabalhando e produzindo em prol do desenvolvimento da região e da população. Percebendo que 0 "semiárido não é um espaço improdutivo. Nele crescem e vivem animais, plantas e árvores nativas. As pessoas plantam e colhem. Chove no Semiárido, se não de modo abundante, mas de modo suficiente para assegurar a vida" (BAPTISTA; CAMPOS, p. 54, 2013).

A política de convivência com o semiárido parte também de um educação contextualizada para a inserção de conceitos em que a população seja informada entendendo o seu funcionamento e se adequando ao contexto. Desmistificando a ideia de uma região problema, onde nada cresce e se desenvolve. Nas palavras de Malvezzi (2007 p. 9 -10):

O Semiárido brasileiro não é apenas clima, vegetação, solo, sol, água. É povo, música, festa, arte, religião, política, história. É processo social. Não se pode compreendê-lo de um ângulo só. Traz consigo uma identidade cultural para além do clima e do bioma. É o Semiárido mais chuvoso do planeta: a pluviosidade é, em média, $750 \mathrm{~mm} / \mathrm{ano}$ (variando, dentro da região, 250 $\mathrm{mm} / \mathrm{ano}$ a $800 \mathrm{~mm} / \mathrm{ano})$. É também o mais populoso, e em nenhum outro as condições de vida são tão precárias como aqui. O subsolo é formado em $70 \%$ por rochas cristalinas, rasas, o que dificulta a formação de mananciais perenes e a potabilidade da água, normalmente salinizada. Por isso, a captação de água de chuva é uma das formas mais simples, viáveis e baratas para se viver bem na região. 
Portanto, o semiárido possui imensa riqueza na sua fauna, vegetação e cultura, não se pode considerar apenas os aspectos climáticos da região. Ainda necessitamos mudar o imagético das pessoas sobre a região nordeste. $O$ segredo para se viver bem no semiárido é entendendo o funcionamento do clima e se adequando a ele, através de ações inteligentes levando em consideração não somente a questão da água, mas agroecológicas, ambientais e uma educação contextualizada voltada para o incentivo a permanência do homem no semiárido.

\section{Tecnologias sociais de convivência com o semiárido}

Por depender de fatores meteorológicos a região nordeste sofre com a limitação de recursos hídricos, por essa razão, foram pensadas estratégias de captação e armazenamento de água para atender as necessidades humanas e também para o desenvolvimento de outras atividades. Soluções que permitam a permanência da população rural na região.

Com a nova forma de pensar o semiárido, foram desenvolvidas tecnologias que se adequasse a realidade da região. Organizações não governamentais passaram a atuar na criação de ações para o desenvolvimento do semiárido, permitindo uma convivência com nosso clima e não combatê-lo. Entre essas organizações, foi criada a Articulação do Semiárido Brasileiro (ASA). Através desta, por volta dos anos 2000 surgiu o programa Um Milhão de Cisternas Rurais (P1MC):

Buscando a construção de um milhão de cisternas para coleta de água da chuva para consumo humano nos estados do Semi-árido ${ }^{3}$ brasileiro: Bahia, Sergipe, Alagoas, Pernambuco, Paraíba, Rio Grande do Norte, Piauí, Ceará e Minas Gerais. Para sua execução conta ao longo dos tempos, com recursos do Ministério do Meio Ambiente, Ministério do Desenvolvimento Social e Combate à Fome, além do apoio de instituições de caráter público ou privado, como a Federação Brasileira dos Bancos (Febraban) (ASSIS, 2010, p. 2).

O objetivo do programa é mostrar que podemos viver bem no semiárido e de maneira sustentável, só precisamos aprender a conviver com ele. Além de tudo, antes de iniciar o programa as famílias são capacitadas e participam de uma formação, por alguns dias em suas comunidades, para aprender técnicas de construção, manejos e de conservação das cisternas. De acordo com Pontes e Machado (2012, p. 18), 
o P1MC é fundamentado em alguns componentes, que seguem uma ordem prático-metodológica. Inicialmente há o processo de mobilização. Nesta etapa são formadas as comissões municipais, executoras e comunitárias e são selecionadas e cadastradas as famílias que receberão as cisternas. Logo após começará a capacitação, que é a formação continuada das equipes técnicas, agentes multiplicadores, pedreiros e habilitação de jovens em confecção e instalação de bombas manuais. A seguir, a construção de cisternas propriamente ditas, envolvendo as famílias e equipes técnicas, desde a demarcação do local da cisterna até a construção propriamente dita, normalmente concluída em cinco dias.

As cisternas domiciliares se configuraram em uma tecnologia de grande valia atendendo a uma necessidade básica da população, que seria água para beber. Ajudando significantemente as comunidades rurais a enfrentarem a falta de água durante os períodos de estiagem.

Porém, esta tecnologia considerada simples necessita de financiamento para ser construída, pois nem todos dispõem de recursos próprios suficientes para a sua construção. Seu valor médio é estimado entre $R \$ 1.500,00$ a $R \$$ 3.000,00, um valor inviável a ser arcado pela população humilde das comunidades rurais. Por essa razão, o programa P1MC foi relevante ao propiciar o acesso à água de qualidade para as famílias.

\section{Materiais e métodos}

A coleta de dados ocorreu em agosto/2019, a partir de questionários e entrevistas com os moradores das comunidades rurais de Cajazeirinha e Minador, em Ipaumirim (CE).

A intenção foi obter informações sobre a efetivação de programas sociais de políticas públicas na região, e se essas ações têm de fato ajudado ou não a população a mitigar a escassez de água nos períodos de estiagem.

De início houve uma conversa com os moradores para explicar o propósito da pesquisa, em seguida foi apresentado um questionário sobre tecnologia de convivência com o semiárido e a funcionalidade das cisternas. Perguntas simples em relação ao antes e depois da implementação das cisternas domiciliares, sobre a capacidade de armazenamento.

O município de Ipaumirim está localizado no Centro-Sul cearense, com população aproximada de 12.305 habitantes, e área territorial de $273,696 \mathrm{Km}^{2}$ (IBGE, 2010). As comunidades estudadas localizam-se próximo ao distrito de Felizardo Vieira possui 26 famílias e um total de 97 indivíduos, das quais 6 famílias não possuem cisternas e utilizam outras fontes para captação de água, 
a principal delas a de poço cacimbão. Cerca de $90 \%$ da população é de baixa renda, sobrevivendo com renda de até um salário mínimo. A principal atividade dessas famílias é a agricultura.

A partir do ano de 2012 os moradores foram contemplados com o programa para a construção de cisternas domiciliares. Estrutura semienterrada feita de alvenaria que capta a água da chuva através de calhas acoplada as cisternas, com capacidade para 16 mil litros de água tem garantido o abastecimento das famílias. A seguir imagem da cisterna domiciliar da comunidade estudada (Figura 1).

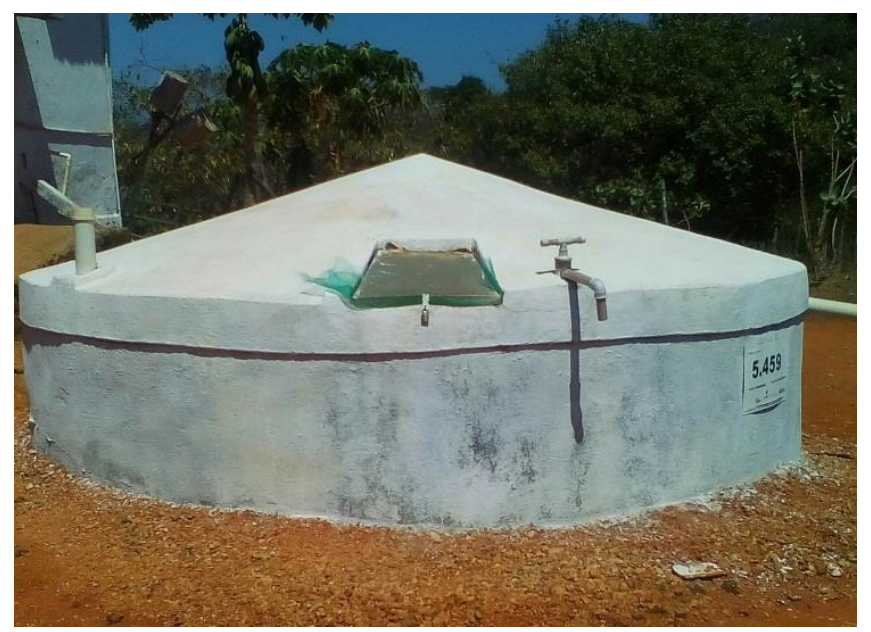

Figura 01: cisterna da comunidade Cajazeirinha. Fonte: acervo da autora (setembro de 2019).

Para avaliar a qualidade da água, foram colhidas amostras de água das cisternas e do poço cacimbão para realizar análises físico-química e microbiológica. Para a análise físico-química foram verificados $0 \mathrm{pH}$, condutividade $\left(\mathrm{mS} \mathrm{cm}^{-1}\right)$, sólidos totais (ST), cloreto $\left(\mathrm{Cl}^{-}\right)$e dureza, de acordo com os valores estabelecidos pela nova Portaria do Ministério da saúde ํo $5 / 2017$.

$\mathrm{Na}$ análise microbiológica foram verificadas a presença ou ausência de coliformes totais a $35{ }^{\circ} \mathrm{C}$ e $45^{\circ} \mathrm{C}$ com testes de tubos múltiplos com série de três tubos: $10 \mathrm{ml} ; 1 \mathrm{ml}$ e 0,1 ml. Foram utilizados replicagem em placas de Petri para identificar presença ou ausência de E. coli. O meio de cultura utilizado foi o caldo verde brilhante para coliformes a $35^{\circ} \mathrm{C}$, o caldo EC para coliformes a $45^{\circ} \mathrm{C}$ e para detectar a presença de $E$. Coli o Agar

Assim, podemos averiguar a potabilidade da água de forma que, os resultados apontem riscos ou ausência de micro-organismos causadores de doenças, nos fornecendo dados que comprovem e assegure o consumo humano desta água e não ofereça riscos à saúde.

A princípio foram coletadas seis amostras de água das cisternas e uma do poço cacimbão, armazenadas em garrafas pets para a análise físico- 
química e para a análise microbiológicas, colhidas em recipientes plásticos para exames laboratoriais. As amostras foram analisadas em laboratório da Universidade Federal de Campina Grande.

\section{Resultados da pesquisa}

De acordo com os dados coletados através das entrevistas e dos questionários, todas as famílias se mostrou satisfeitas com uso das cisternas.

Os moradores contam que tiveram acesso à tecnologia social através da Secretaria Municipal de Agricultura, Recursos Hídricos e Meio Ambiente (Prefeitura Municipal de Ipaumirim).

As famílias relataram a dificuldade antes da chegada das cisternas. $O$ acesso à água era por meio de poço cacimbão e abastecimento por carro pipa, que não atendia a todos e nem era suficiente. Existe na região uma quantidade significativa de poços tipo cacimbão próximos das residências, alguns ainda sendo utilizados. O principal deles possui aproximadamente quinze metros de profundidade (Figura 2).

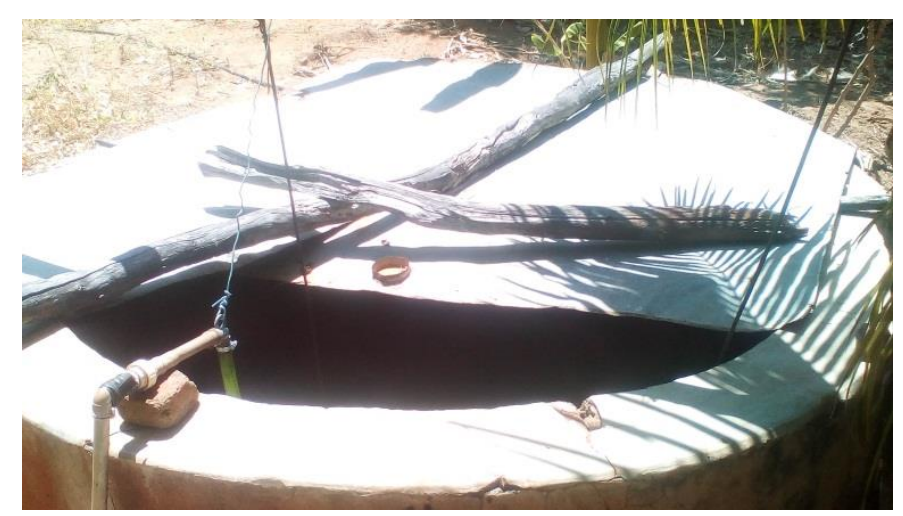

Figura 2: Imagem do principal poço cacimbão. Fonte: acervo da autora (setembro de 2019).

Existe um sistema de encanamento juntamente com um motor, movido a energia elétrica que fornece a água para as residências. Não existe um responsável por gerenciar a distribuição da água e todos que precisam tem acesso livre ao mesmo.

A implantação das cisternas melhorou muito a qualidade de vida da população e trouxe muitos benefícios. Como conta essa beneficiária do projeto:

"Só em ter água na porta de casa e pegar a hora que a gente precisa é muito bom, antes era ruim demais, tinha que pegar água do cacimbão longe que só. Hoje é outra coisa, usamos a água das cisternas para tudo, é suficiente e dá para bastante tempo." (M. S). 
O abastecimento das cisternas é suficiente e, na maioria das vezes, dá para o ano todo. Mas quando o volume de chuvas não é considerável para encher totalmente as cisternas, completam com água de poço cacimbão. Em relação à manutenção das cisternas, os próprios moradores se encarregam de fazer reajustes, se necessário, limpeza e tratamento. Outro beneficiário relata que:

"Depois que essas cisternas chegaram aqui só vi benefícios, foi a melhor coisa que já aconteceu aqui para nós, à água é muito boa e limpa, dá para gente aqui de casa e para os bichos que a gente cria. Nós que fazemos a limpeza da cisterna, lavamos e pintamos para manter sempre conservada, por que uma coisa que é boa assim tem que cuidar, né?" (D. S).

Em contra partida, há famílias que não possuem cisternas. Ao serem questionadas por tal fato, umas revelaram que não quiseram por já terem acesso à outra fonte de água e não viram necessidade de construí-las. Outras se encontravam ausentes na ocasião e não puderam autorizar a construção da referida tecnologia.

Das 26 famílias apenas duas não usam a cisterna, elas foram construídas, mas apresentaram defeitos que não foram reparados nem pelos técnicos responsáveis nem pelos próprios moradores. Ou seja, não são utilizadas e usam a água do poço cacimbão para os afazeres domésticos e compram água para beber.

De acordo com os resultados da análise físico-química a água possui uma qualidade considerada dentro dos padrões de potabilidade e na análise microbiológica foi detectada uma baixa presença de coliformes totais (Tabelas 1, 2 e 3).

Tabela 1: Análise físico-química.

\begin{tabular}{|l|c|c|c|c|c|}
\hline & $\mathbf{p H}$ & $\begin{array}{c}\text { CONDUTIVIDADE } \\
\left(\mathbf{m S} / \mathbf{c m}^{-1}\right)\end{array}$ & $\begin{array}{c}\text { SÓLIDOS } \\
\text { TOTAIS (ST) }\end{array}$ & $\begin{array}{c}\text { CLORETO } \\
(\mathbf{C l})\end{array}$ & $\begin{array}{c}\text { DUREZA } \\
\left(\mathbf{m g} / \mathbf{l}^{-1}\right)\end{array}$ \\
\hline $\begin{array}{l}\text { CISTERNA 01 } \\
\text { MINADOR }\end{array}$ & 7.30 & 711 & 670 & 0,9 & 1.3 \\
\hline $\begin{array}{l}\text { CISTERNA 02 } \\
\text { MINADOR }\end{array}$ & 8.68 & 423 & 397 & 7.1 & 1.6 \\
\hline $\begin{array}{l}\text { CISTERNA 03 } \\
\text { CAJAZEIRINHA }\end{array}$ & 8.18 & 222 & 217 & 1.1 & 4.4 \\
\hline $\begin{array}{l}\text { CISTERNA 04 } \\
\text { CAJAZEIRINHA }\end{array}$ & 7.95 & 357 & 335 & 15.2 & 3.2 \\
\hline $\begin{array}{l}\text { CISTERNA 05 } \\
\text { CAJAZEIRINHA }\end{array}$ & 8.6 & 557 & 520 & 0.8 & 1.6 \\
\hline $\begin{array}{l}\text { CISTERNA 06 } \\
\text { CAJAZEIRINHA }\end{array}$ & 7.13 & 658 & 620 & 8.0 & 6.3 \\
\hline CACIMBÃO & 7.23 & 350 & 336 & 5.9 & 4.0 \\
\hline
\end{tabular}


Tabela 2: Análise microbiológica / coliformes a $35^{\circ} \mathrm{C}$

\begin{tabular}{|l|c|c|c|}
\hline & $\mathbf{1 0} \mathbf{~} \mathbf{l}$ & $\mathbf{1} \mathbf{~} \mathbf{l}$ & $\mathbf{0 , 1} \mathbf{~ m l}$ \\
\hline CISTERNA 01 - MINADOR & 2 & 0 & 0 \\
\hline CISTERNA 02 - MINADOR & 0 & 0 & 0 \\
\hline CISTERNA 03 - CAJAZEIRINHA & 3 & 3 & 3 \\
\hline CISTERNA 04 - CAJAZEIRINHA & 2 & 2 & 2 \\
\hline CISTERNA 05 -CAJAZEIRINHA & 3 & 2 & 1 \\
\hline CACIMBÃO & 3 & 2 & 1 \\
\hline
\end{tabular}

Tabela 3: Análise microbiológica / coliformes a $45^{\circ} \mathrm{C}$

\begin{tabular}{|l|c|c|c|}
\hline & $\mathbf{1 0} \mathbf{~ m l}$ & $\mathbf{1} \mathbf{~ m l}$ & $\mathbf{0 , 1} \mathbf{~ m l}$ \\
\hline CISTERNA 01 - MINADOR & 0 & 0 & 0 \\
\hline CISTERNA 02 - MINADOR & 0 & 0 & 0 \\
\hline CISTERNA 03 - CAJAZEIRINHA & 3 & 3 & 3 \\
\hline CISTERNA 04 - CAJAZEIRINHA & 2 & 1 & 1 \\
\hline CISTERNA 05 -CAJAZEIRINHA & 3 & 3 & 1 \\
\hline CACIMBÃO & 3 & 3 & 2 \\
\hline
\end{tabular}

Também foi feita a verificação em placas de Petri para determinar a presença ou ausência de $E$. Coli, essa amostra foi colhida da cisterna de no 5 da comunidade Cajazeirinha (Figura 3).

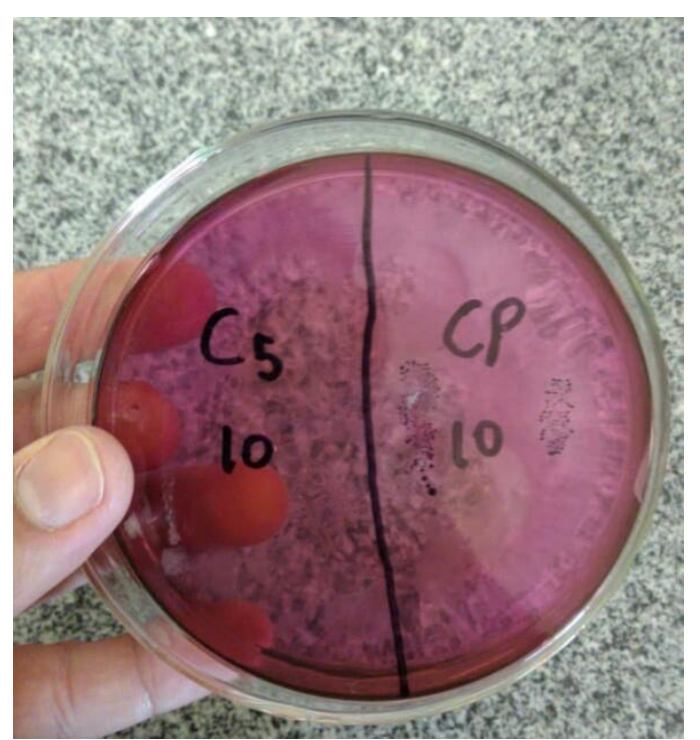

Figura 3: replicagem em placa de Petri Fonte: acervo da autora (setembro de 2019).

Podemos observar na figura que está amostra indica a ausência de $\mathrm{E}$. Coli, justamente pela forma como a coloração se apresenta. O que indicaria a presença desse tipo de bactéria seria se esta coloração estivesse verde. Constatando assim, que as amostras analisadas deram negativas para a presença de micro-organismos. 


\section{Conclusão}

Podemos dizer que a região nordeste é mal compreendida, ainda vista sob um olhar preconceituoso, um lugar de miséria, seca, fome e desesperança. Bem verdade, que as nossas condições climáticas não nos favorecem muito, mas isso não deve ser considerado um empecilho para o desenvolvimento da região e melhoria na qualidade de vida da população. Conhecemos a realidade climática da região e entendamos que a seca não é um fenômeno recente, ela sempre existiu e continuará existindo, sabendo disso, não deveríamos ser sempre pegos de surpresa.

Os programas de políticas públicas criados pelos governos federal e estadual voltados para o semiárido brasileiro, com o propósito de mitigar a escassez de água nos períodos de seca no nordeste brasileiro, tem sido campo de estudo de inúmeros pesquisadores quanto a sua eficácia e funcionalidade. A partir da fundação da ASA e o desenvolvimento de programas como Um Milhão de Cisternas (P1MC), observou-se a inserção de propostas inovadoras que tem contribuído consideravelmente para a convivência com o semiárido.

Isso mostra que o problema não está somente no clima, mas também na falta de políticas públicas estruturantes eficazes e técnicas que possibilite a convivência com o semiárido e a permanência do homem nele.

Em vista disso, podemos concluir que as políticas públicas, em especial as cisternas domiciliares, tem proporcionado inúmeros benefícios para os moradores, facilitando o acesso a água e melhorando a qualidade de vida. $\mathrm{O}$ volume de água armazenado nas cisternas é considerado suficiente para atender as necessidades básicas das famílias, o resultado das análises mostra que a água está dentro dos padrões de potabilidade e não oferece riscos a saúde dos moradores. O resultado obtido pelo o estudo mostrou que a funcionalidade do programa de fato acontece. Pelo menos nas comunidades citadas, as famílias estão satisfeitas com a referida tecnologia e utilizam a água de maneira consciente.

\section{Referências}

ASSIS, T. R.P. Sociedade Civil e a Construção de Políticas Públicas na Região: o caso do Programa Um Milhão de Cisternas Rurais (P1MC). Revista de Políticas Públicas, v.16, n.1, pp.179-189, 2012.

BAPTISTA, N.Q.; CAMPOS, C.H. Fatores históricos, sociais, culturais e políticos do semiárido. In: CONTI, I.L.; SCHROEDER, E.O. (Orgs.). Estratégias de convivência com o semiárido brasileiro: Autonomia e Protagonismo Social. Brasília, IABS, 27-34, 2013.

BRASIL. Ministério da Saúde. Fundação Nacional de Saúde. Manual técnico de análise de água para consumo humano. Brasília: Funasa, 2013.

BRITO, L.T.L. et al. Cisternas domiciliares: água para consumo humano. Embrapa Semiárido-Capítulo em livro científico. ALICE, v., pp.81-101, 2007. 
CAMPOS, J.N.B. Secas e políticas públicas no semiárido: ideias, pensadores e períodos. Estudos Avançados, v.28, pp.65-88, 2014.

CONTI, I.L.; SCHROEDER, E.O. Convivência com o Semiárido Brasileiro: Autonomia e Protagonismo Social. Brasília: IABS, 2013.

CHAGAS, M. F. V.; ROLIM, R. V. Em Família. Cajazeiras, Gráfica Real, 2004.

DA SILVA, P.C.G. et al. Caracterização do Semiárido brasileiro: fatores naturais e humanos. Embrapa Semiárido - Capítulo em livro científico. ALICE, pp.18-48, 2010.

DE ANDRADE, J.A.; NUNES, M.A. Acesso à água no Semiárido Brasileiro: uma análise das políticas públicas implementadas na região. Revista Espinhaço UFVJM, pp.28-39, 2017.

IBGE -Intituto Brasileiro de Geografia e Estatística. Censo Populacional 2010. Disponível em <https://cidades.ibge.gov.br>.

INS - Instituto Nacional do Semiárido. Semiárido brasileiro ultrapassa 23,5 milhões de habitantes. 2017. Disponível em <http://www.brasil.gov.br>.

PASSADOR, C.S. Apontamentos sobre as políticas públicas de combate à seca no Brasil: cisternas e cidadania? Cadernos Gestão Pública e Cidadania, v.15, pp.65-86, 2010.

PONTES, E.T.M.; MACHADO, T.A. Desenvolvimento sustentável e convivência com o semi-árido: o caso do programa um milhão de cisternas rurais no nordeste brasileiro. Encontro Nacional de Geografia Agraria, v.19, 2012.

LIMA, A.E.F.; DA SILVA, D.R.; SAMPAIO, J.L.F. As tecnologias sociais como estratégia de convivência com a escassez de água no semiárido cearense. Conexões-Ciência e Tecnologia, v.5, pp.9-21, 2011.

MALVEZZI, R. Semiárido: uma visão holística. CONFEA, Brasília, 2007.

SILVA, R.M.A. Entre dois paradigmas: combate a seca e convivência com o semiárido. Sociedade e Estado, v.18, n.1-2, pp.361-385, 2003.

SCHISTEK, H. O Semiárido Brasileiro: uma região mal compreendida. In: CONTI, I.L.; SCHROEDER, E.O. (Orgs.). Convivência com o Semiárido Brasileiro: Autonomia e Protagonismo Social. Brasília, IABS, pp.61-72, 2013.

SUASSUNA, J. Semiárido: Proposta de Convivência com a Seca, Fundação Joaquim Nabuco, Recife, 2002. 